\title{
The Role of the Laboratory in Design Engineering Education
}

\author{
Brian Surgenor and Kevin Firth \\ Department of Mechanical and Materials Engineering \\ Queen's University, Kingston, Ontario, K7L 3N6 \\ surgenor@me.queensu.ca
}

\begin{abstract}
This paper discusses the role of the laboratory in engineering design education, and specifically, how laboratories can be used to help meet elements of the CEAB requirements for engineering design and in doing so, complement the objectives of design project courses. Examples are taken from two courses offered at Queen's University:1) automatic control systems and 2) mechatronics engineering.
\end{abstract}

\section{Introduction}

In the early days of engineering education, instructional laboratories were an essential part of undergraduate programs as they were the only source of the hands-on instruction that was needed to complement the engineering science that was taught in the lecture hall. In a way, laboratories with students working in groups were the first acknowledgement that the best way to teach was to "practice by doing" and "teach others". This observation is illustrated in Figure 1, as taken from the text by Singhal, Bellamy and McNeill [1], which makes the point pictorially that the "lecture" is the least effective method of teaching, from a retention standpoint. The "practice by doing" element is also implicitly followed by instructors who believe that the design process is not complete, and the educational impact much less effective, unless the build and test phase of the process is included in

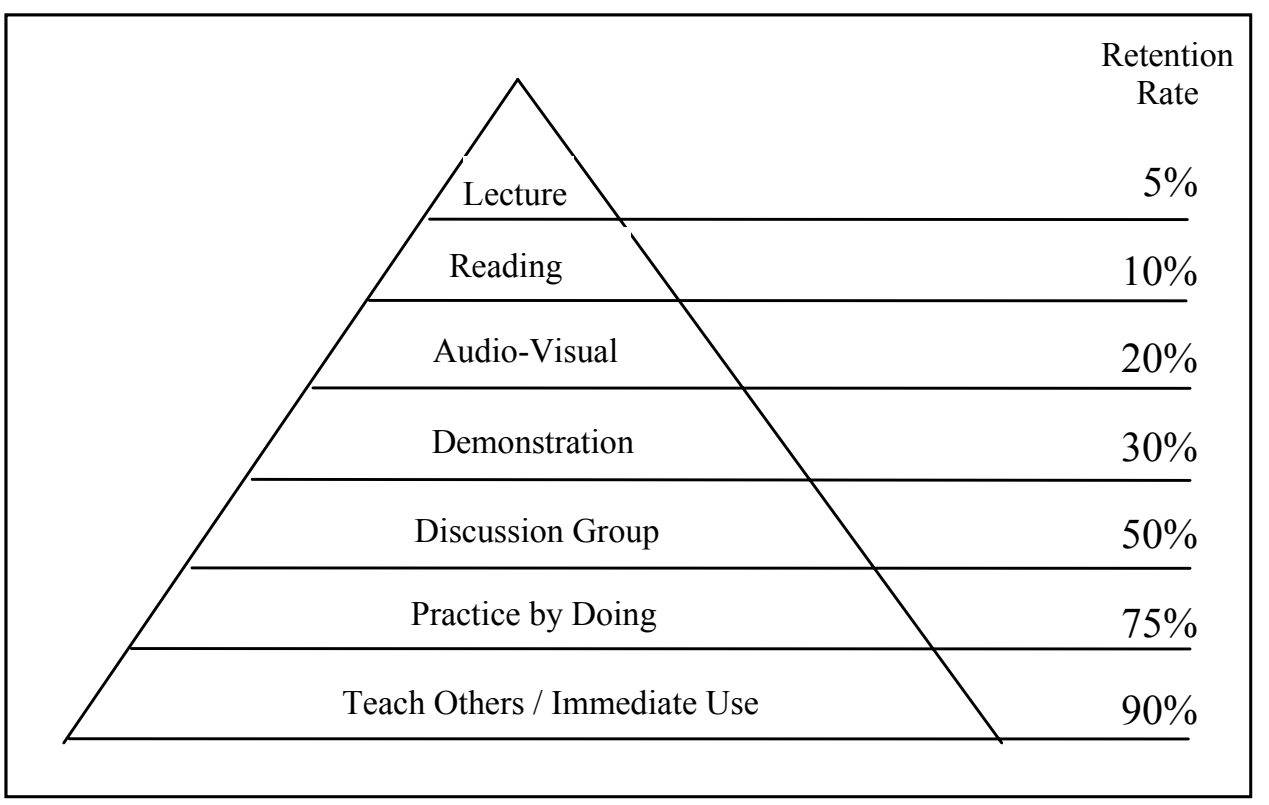

Figure 1. Teaching methods and retention [1] 
design project courses [2]. And although the main reason for requiring students to work in teams in design projects is to provide students with experience in team work, one must also recognize that there is an element of "teach others" in the practice.

In recent years, the focus of curriculum development has been on the introduction of team based design projects throughout the curriculum, not just in the final year. When a program is subject to an accreditation review, it is these design projects that are put forward as the primary evidence of the "engineering design" (ED) units in a program. In parallel to this development, one can observe a decline in the stature of traditional laboratories as a mechanism to deliver instruction in hands-on engineering and in particular the design process. A review of current laboratories reveals that many have fallen into the "cookbook" style that rarely challenges the creative or problem solving capabilities of a student, and they are often performed in large groups, significantly diminishing any educational value that the exercises were intended to have.

The Canadian Engineering Accreditation Board (CEAB) defines design as the process that integrates mathematics, basic sciences, engineering sciences and complementary studies in developing elements, systems, and processes to meet specific needs [3]. Furthermore, it identifies design as a creative, iterative and often open-ended process subject to constraints. The CEAB requires that an engineering curriculum culminate in a significant design experience which is based on the knowledge and skills acquired in earlier course work and which preferably gives students exposure to the concepts of team work. Most engineering programs have fourth year capstone team design project courses that fulfill this requirement.

This paper discusses the role of the laboratory in engineering design education, and specifically, how laboratories can be used to help meet elements of the CEAB requirements for engineering design and in doing so, complement the objectives of capstone design courses. The approaches to laboratories in a Mechatronics Engineering course and an Automatic Control Systems course will be used as examples.

\section{Instructional Laboratories}

It is useful to distinguish between three basic types of engineering laboratories: development, research and educational [4]. While they have many characteristics in common, there are differences. These differences must be acknowledged if there is to be agreement on the educational objectives for instructional laboratories. It is interesting to note that all three kinds of laboratories can be found in a university setting.

Practicing engineers go to the development laboratory for two reasons: 1) to obtain experimental data to guide them in the design and development of a product and 2) to determine if a design performs as intended. While a development laboratory is intended to provide immediate answers to questions, a research laboratory is used to seek broader knowledge that can be generalized, often without a specific use in mind. Finally, when undergraduate students go to an instructional laboratory, they do so to learn something that practicing engineers are assumed to already know. That "something" needs to be well defined through the careful design of learning objectives if the considerable resources devoted to instructional laboratories is to be justified.

In the past two or three decades, several engineering education scholars have spoken to the issue of learning objectives. Beginning with Bloom [5], various taxonomies of learning objectives have been developed that help to explain the concept of objectives. However, the literature is relatively silent on the learning objectives associated in engineering instructional laboratories. The majority of papers on the subject of laboratories tend to take the objectives for granted and simply report on the nature of the apparatus and the success of the students in accomplishing a desired task [4]. Furthermore, given the decline in the practical skill development that used to occur outside of school, there has been a trend to use laboratories solely for the purpose of giving students the "look and feel" of physical systems [6].

In 2002, a group of fifty engineering educators met and developed a list of thirteen objectives for instructional laboratories [7] These objectives are summarized in Table 1. The group considered these to be "the fundamental objectives of engineering instructional laboratories". If one reflects on the objectives given in this table, one recognizes that they could just as readily be labeled as "objectives of an engineering curriculum". Thus, it should be no surprise that if one puts the instructional objectives of a laboratory beside the instructional objectives of a design course, the two sets of objectives are very similar. Table 2 gives a sample set of learning objectives for a first year design course [8]. Although organized differently, a review of the keywords shows that Table 1 and Table 2 are remarkably similar. Furthermore, the objectives of a senior or capstone design course are also very similar [9]. One could even conclude that instructional objectives for design are a subset of the instructional objectives for a laboratory. On the other hand, one acknowledges that in practice, laboratories often do not fulfill any of the objectives given in Table 1 . 
Table 1: Objectives of instructional laboratories, adapted from [7]

\begin{tabular}{|l|l|l|}
\cline { 2 - 3 } \multicolumn{1}{l|}{} & \multicolumn{1}{|c|}{ Objective } & \multicolumn{1}{c|}{ Details } \\
\hline 2 & Instrumentation & $\begin{array}{l}\text { Apply appropriate sensors, instrumentation, and/or software tools to make } \\
\text { measurements of physical quantities. }\end{array}$ \\
\hline 3 & Experiment & $\begin{array}{l}\text { Identify the strengths and limitations of theoretical models as predictors of real-world } \\
\text { behaviors. }\end{array}$ \\
\hline 4 & $\begin{array}{l}\text { Devise an experimental approach, specify appropriate equipment and procedures, } \\
\text { implement these procedures and interpret the results or data to characterize an } \\
\text { engineering material, component, or system. }\end{array}$ \\
\hline 5 & Design & $\begin{array}{l}\text { Demonstrate the ability to collect, analyze, and interpret data, and to form and support } \\
\text { conclusions. }\end{array}$ \\
\hline 6 & Learn from Failure & $\begin{array}{l}\text { Design and build a product or system; meeting client requirements; developing system } \\
\text { specification from requirements; and testing and debugging a prototype using } \\
\text { appropriate tools to satisfy requirements. }\end{array}$ \\
\hline 7 & Creativity & $\begin{array}{l}\text { Demtify unsuccessful outcomes due to faulty equipment, parts, code, construction, } \\
\text { process, or design, and then re-engineer effective solutions. } \\
\text { real-world problem solving. }\end{array}$ \\
\hline 8 & Psychomotor & $\begin{array}{l}\text { Demonstrate competence in selection, modification, and operation of appropriate } \\
\text { engineering tools and resources. }\end{array}$ \\
\hline 9 & Safety & $\begin{array}{l}\text { Identify health, safety, and environmental issues related to technological processes and } \\
\text { activities, and deal with them responsibly. }\end{array}$ \\
\hline 10 & Communication & $\begin{array}{l}\text { Communicate effectively about laboratory work with a specific audience, both orally } \\
\text { and in writing, at levels ranging from executive summaries to comprehensive technical } \\
\text { reports. }\end{array}$ \\
\hline 11 & Teamwork & $\begin{array}{l}\text { Work effectively in teams, including structure individual and joint accountability; } \\
\text { assign roles, responsibilities, and tasks; monitor progress; meet deadlines; and integrate } \\
\text { individual contributions into a final group report. }\end{array}$ \\
\hline 12 & Ethics & $\begin{array}{l}\text { Behave with highest ethical standards, including reporting information objectively and } \\
\text { interacting with integrity. }\end{array}$ \\
\hline 13 & Sensory Awareness & $\begin{array}{l}\text { Use human senses to gather information and to make sound engineering judgments in } \\
\text { formulating conclusions about real-world problems. }\end{array}$ \\
\hline
\end{tabular}

Table 2: Learning objectives of a design course, adapted from [8]

\begin{tabular}{|l|l|l|}
\cline { 2 - 3 } \multicolumn{1}{c|}{} & \multicolumn{1}{|c|}{ Objective } & \multicolumn{1}{c|}{ Details } \\
\hline 1 & Design Process & $\begin{array}{l}\text { To learn through experience the engineering design process, including: statement of } \\
\text { need, information gathering and research, concept generation and innovation, } \\
\text { identification of objectives and constraints, justification of final design choice, design } \\
\text { iteration, application of engineering science, project budgeting. }\end{array}$ \\
\hline 2 & Teamwork & $\begin{array}{l}\text { To develop teamwork and individual skills, including: individual responsibility and } \\
\text { accountability, dispute-resolution, team meetings, team communications and project } \\
\text { management (setting goals, prioritizing taks, and meeting deadlines). }\end{array}$ \\
\hline 3 & Communication & $\begin{array}{l}\text { To communicate technical information in oral, written and graphical forms, including: } \\
\text { preparation, documented research, content (what is presented), mechanics (how it is } \\
\text { presented) and delivery. }\end{array}$ \\
\hline 4 & Reflection & $\begin{array}{l}\text { To reflect on one's achievements, recognizing ways to improve, including: learning } \\
\text { from failures and personal growth towards becoming a Professional Engineer. }\end{array}$ \\
\hline
\end{tabular}




\section{Control Laboratory Example}

MECH 350 Automatic Control Systems is a third year core course with an enrolment of approximately 175 to 200 students. The content is typical of that found in most mechanical engineering programs on this subject: modes of control, principles of feedback, Laplace and transfer functions, transient response of first and second order systems, stability criteria, root locus, Bode and frequency response. A set of six "mini-labs" is given as part of the course.

- $\quad$ Lab \#1 - Introduction to the apparatus and open loop motor speed control

- $\quad$ Lab \#2 - Motor simulation with MATLAB

- Lab \#3 - P and PI closed loop motor speed control

- $\quad$ Lab \#4 - P and PV closed loop motor position control

- Lab \#5 - Bode, root locus and time domain analysis with MATLAB

- $\quad$ Lab \#6 - Light assembly control with a programmable logic controller (PLC)

The stated objective of the laboratories is to expose students to the hardware and software aspects of automatic control systems.
Each laboratory is one hour in length and the students work in pairs (as illustrated in Figure 2). A written group report must be submitted before the end of the laboratory. Twenty-two students can be handled in each one-hour session. Thus, with eight sessions scheduled per week, the entire class can be complete each laboratory in almost one week.

Aside from their short (one hour) duration, these laboratories are organized conventionally:

- Background material on the theory is covered by lectures given prior to the laboratory

- Students follow a written procedure

- Everyone has the same equipment that is setup by technicians in turn key fashion

- $\quad$ Students record their results and submit their conclusions in the form of a written report.

The main learning objective of these labs is to reinforce the lecture material. Consequently, there is active coordination between the timing of the lectures and the timing of the laboratories. The mechanical and electrical components of the system being tested are "well-behaved" and directly controllable by the students. Given the number of students and tight timelines, hardware (and software) failures are to be avoided and system reliability is paramount.

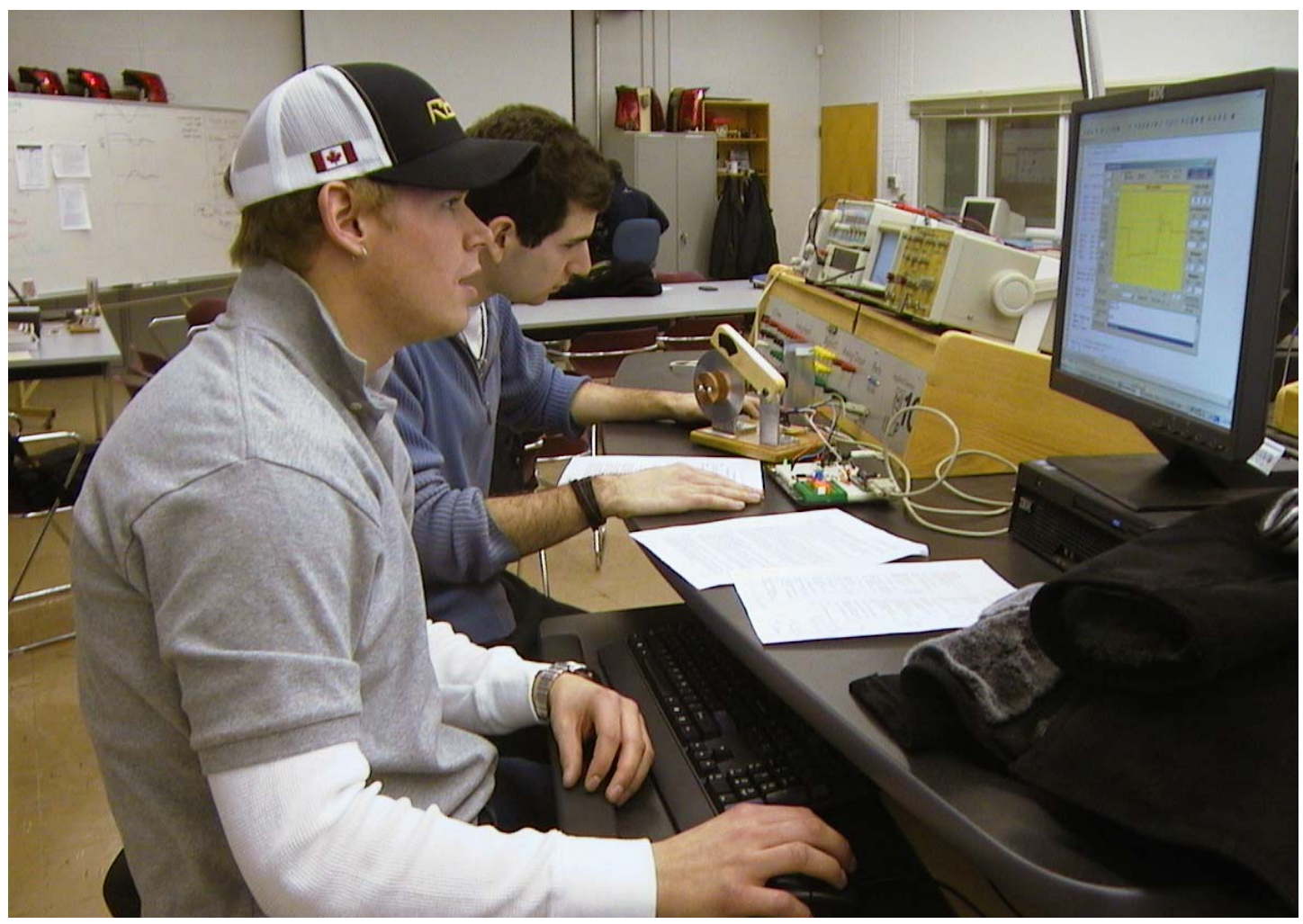

Figure 2: Automatic control laboratory, motor speed control, students working in pairs 


\section{Mechatronics Laboratory Example}

MECH 452 Mechatronics Engineering is a fourth year elective course with an enrolment of 40 students. The course objective is to extend a student's working knowledge of engineering to include applied electronics and microcontrollers. The course is designed around a laboratory sequence using a microcontroller based prototyping board and a mobile robot that was designed in-house. The labs alternate between applying the technology to the prototyping board in one week, and then applying the same technology to the mobile robot in the following week:

- Lab \#1 and Lab \#2, navigation by contact sensing (limit switches)

- $\quad$ Lab \#3 and Lab \#4, navigation by light sensing (photoresistor mounted on a servomotor)

- $\quad$ Lab \#5 and Lab \#6, navigation by ranging (infrared sensor, with Lab \#6 illustrated in Figure 3 where the robot is required to follow the centerline of a test track)

- $\quad$ Lab \#7 and Lab \#8, navigation by RF (wireless communication)

The laboratories are conventional in the sense that they are relatively tightly scripted. A handout details the procedure and every group works with the same component hardware. Variation between groups arises from the programming and in the handling of the sensors, actuators and supporting electric circuits.

For these laboratories, students work in pairs, and this occupies the first eight weeks of the course. The underlying goal is to introduce the students to the technology such that they become comfortable with the technology and gain confidence in their own abilities. As shown in Figure 3, one aspect of these labs is that even though the students work in pairs, the performance evaluation is done as a group.

In the final four weeks of the course, the experience and knowledge gained in the laboratories is applied to a team design project. In this case, "team" means eight students working together with four robots. To date, the project has involved a problem that mimics a team of autonomous robots trying to find and isolate multiple landmines (represented as lights). This particular task was chosen as it makes use of all of the technology learned in the first part of the course. Also, it models a very real and significant application of multiple autonomous mobile robots (landmine detection and isolation). Figure 4 illustrates the development phase of the project. The students learn very quickly that one of the biggest problems is that of spurious and faulty sensor readings. Considerable design time is spent addressing this problem, typically by the application of redundant sensors in combination with innovative programming.

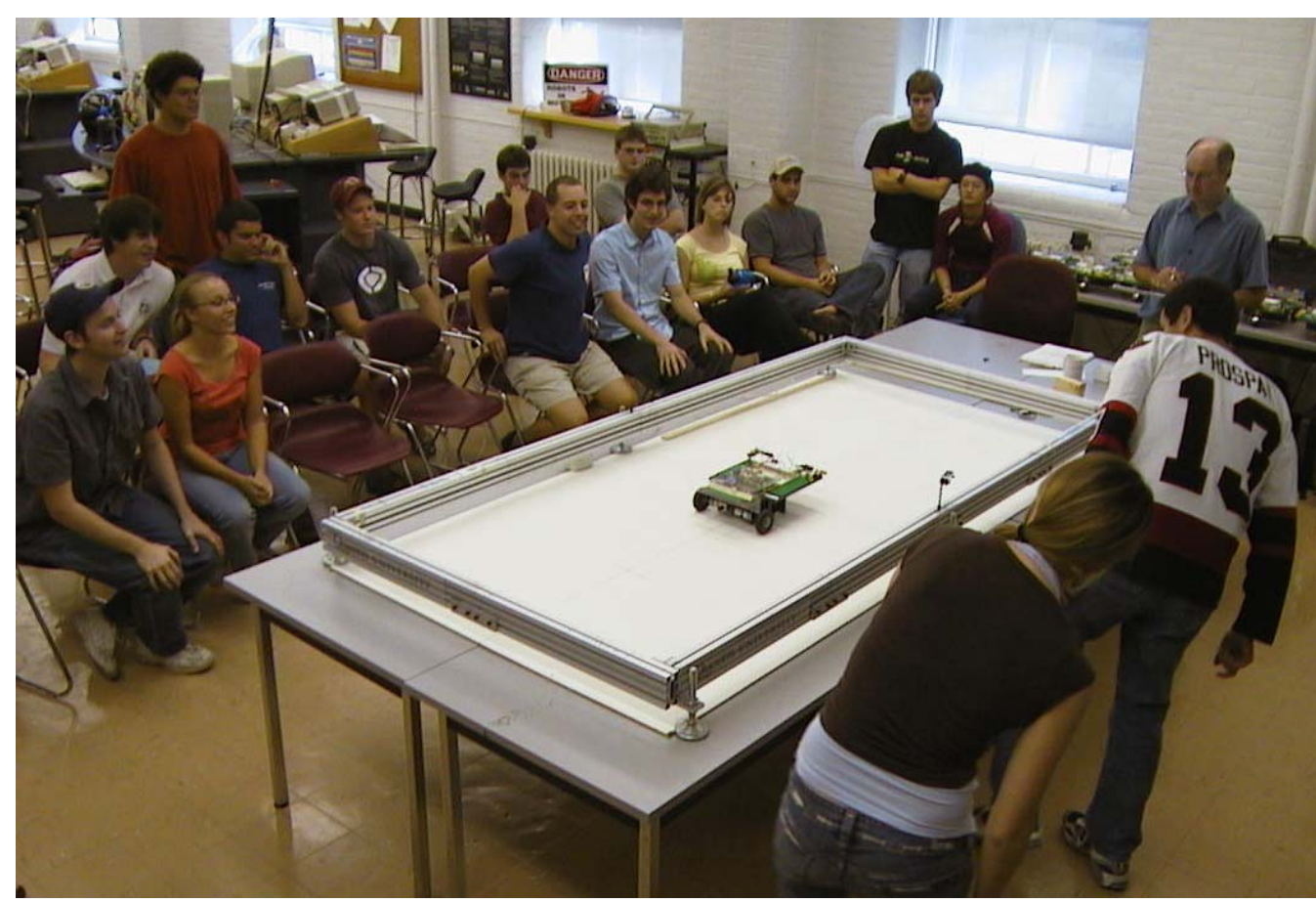

Figure 3: Mechatronics laboratory, mobile robot position control, students work in pairs, but the performance evaluation is done as a group 


\section{Discussion}

The two examples of laboratories presented here require significant material, instrumentation and teaching staff resources. However, their worth needs to be considered with the understanding that the value of these laboratories goes beyond their being interesting supplements to the lecture material. They make contributions to meeting the $\mathrm{CEAB}$ engineering curriculum requirements, and in particular, they provide preparation for a student's design project experience, be it the design project in $\mathrm{MECH} 452$ or the design project in the capstone design course.

Taken simply as laboratory experience these courses meet the letter of the CEAB laboratory requirement given as Section 2.2.6: "Appropriate laboratory experience must be an integral part of the engineering curriculum..." [3]. Looking more deeply into how the laboratories meet many of the objectives of an instructional laboratory and of a design course, as listed in Tables 1 and 2, we can see how they contribute to the fulfillment of the CEAB requirements for design.

The MECH 350 Automatic Control Systems laboratories clearly address laboratory objectives 1,2 , $3,4,8,10,11,13$ in Table 1 . However, they do not address all of those objectives in their entirety. For example, the students in the control labs do not "devise an experimental approach" or "specify appropriate equipment and procedures", as stated in Objective 3 (Experiment). However, they do "implement these procedures and interpret the result data to characterize an engineering system”.
The test apparatus and instrumentation that are already selected and prepared for the student must be explained well, if the learning in these laboratories is to contribute substantially to a future design project. It then becomes a familiar example of a working model. The students can draw upon this when they need to formulate their own designs later on.

Repeating the contact with the equipment over several minilabs contributes to Objective 13 (Sensory Awareness) and Objective 8 (Psychomotor) given in Table 1. Essentially, the students gain confidence in using the test bed and the instrumentation software for the laboratory. More broadly, they gain confidence in their own ability to apply these tools.

As well, these laboratories can be seen as moving forward on Objective 1 (Design Process) of Table 2, "to learn through experience the engineering design process, including ... information gathering and research". The laboratories contribute to what the CEAB identifies as "... skills acquired in earlier course work ..." [3] that form the basis for the significant design experience of the capstone course.

The MECH 452 Mechatronics Engineering course goes significantly further with laboratory focused learning. It meets essentially all of the objectives of an instructional laboratory, Table 1, and those of a design course as shown in Table 2. Concomitantly, it makes significant contributions to student design experience and to student preparedness for work on a capstone design project.

Two objectives with similar descriptions in both Tables 1 and 2, which stand out especially in the mechatronics course, are Objective 5 (Design) and

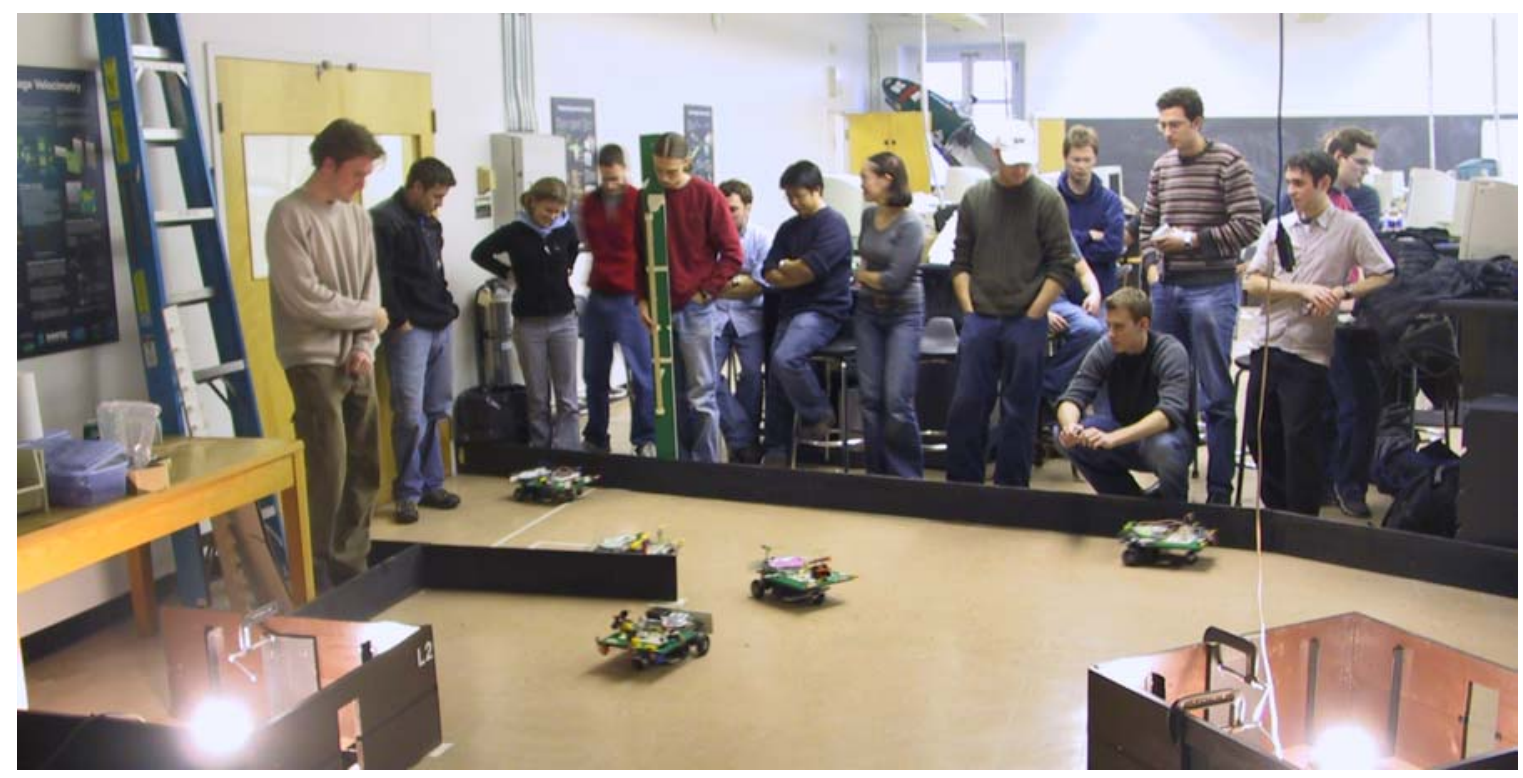

Figure 4. Mechatronics team design project, testing in development phase 
Objective 6 (Learn from Failure). In the controlled environment of the laboratory it is possible for students to quickly build up the basic knowledge they need about the way the robot hardware, software and sensor systems work. They soon move into the creative, iterative process of designing the robot's hardware arrangement and software program to do specific tasks, which is a paraphrase part of the CEAB design requirement given as Section 2.2.3 [3].

Aside from the subject matter, one different aspect of the MECH 452 laboratories is that even though the students work in pairs at their own workstations for the development phase (similar to Figure 2), the "testing" phase is conducted as a group, as illustrated in Figure 3. The immediately obvious impact of group observation of the testing demonstrations is the level of effort that performing in front of your peers inspires. Beyond the quest for marks, students clearly take pride in a successful demonstration and associate "coolness" with a particularly creative and elegant solution. Laughter is in the room and everybody claps and applauds each other's performance.

There is significantly more than a motivational benefit in this process though. Viewing a series of demonstrations that include various design solutions to the same problem, with essentially the same equipment, presents an excellent opportunity for discussing the problem solving process. This is especially effective because everyone shares a very good understanding of the task context.

Issues such as reliability, redundancy, noise, sensitivity to a changing supply voltage, code size, response time and the smoothness of motion are points of discussion for the instructors, the presenters and the student audience.

Striking examples of previously studied key concepts are bound to occur. For instance, the robot behaviors resulting from open loop or closed loop control are clearly different. The course instructor can expand the thinking about these ideas to include the evaluation of their merit given the task at hand. How much programming and testing effort did the different solutions require, and was it worth it in light of what was required to meet the test criteria?

Frequently, students in MECH 452 spend time discussing their capstone design projects with the instructors and regularly incorporate some of the mechatronics material into their final design work.

In the process of putting a lot of focus on making an effective teaching laboratory experience for the student, we have noticed a shift in the way that lectures are prepared. While laboratories have long been used to illustrate the points made in the lecture, and they still do, the preparation process has altered.

With the key concepts that we want to illustrate in mind, we look for the laboratory experience that will bring about that particular learning experience. Then the lectures are built to prepare for the laboratory with the essential concepts, background information, and detailed notes on the equipment that the students will use. As well, each lecture following a laboratory will include some review of what was learned, with particular references to what actually happened in the laboratory. The overall focus of the course instruction shifts downward in the "Teaching methods and retention" pyramid of Figure 1, promoting more learning in a higher retention rate setting [1].

\section{Conclusions}

This paper reviewed the role of the laboratory in engineering design education, and specifically, how laboratories can be used to meet elements of the $\mathrm{CEAB}$ requirements for engineering design and in doing so, complement the objectives of design project courses. Examples are taken from two courses offered at Queen's University:1) automatic control systems and 2) mechatronics engineering.

\section{References}

[1] Singhal, A.C, Bellamy, L. and McNeill, B. "A New Approach to Engineering Education”, Arizona State University, Arizona, pp. 88, 1997.

[2] Mechefske, C.K., Surgenor, B.W., Pelow, J. and Wyss, U.P. "Design Projects: The CDIO Context and Experience with Industry", Proc. $2^{\text {nd }}$ CDEN Int. Design Conf., July 18 to 20, Kananaskis, Alberta, 2005.

[3] Accreditation Criteria and Procedures, Canadian Engineering Accreditation Board, Canadian Council of Professional Engineers, 2005.

[4] Feisel, L.D. and Rosa, A.J. "The Role of the Laboratory in Undergraduate Engineering Education", ASEE Jrnl of Engineering Education, January, pp. 121-130, 2005.

[5] Bloom, B.S. "Taxonomy of Educational Objectives", Longmans and Green, New York, NY, 1956.

[6] Leva, A. "A Hands-On Experimental Laboratory for Undergraduate Courses in Automatic Control," IEEE Trans on Education, Vol. 64, No. 2, pp. 263-272, 2003.

[7] Feisel, L.D. and Peterson, G.C. "A Colloquy on Learning Objectives for Engineering Education Laboratories", Proc. ASEE Annual Conference, June 16 to 19 , Montreal, Quebec, 2002.

[8] Buchal, R., Bartlett, F.M, Hinchberger, S., Barghi, S., Bassi, A., McIaac, K., Sabarinathan, J., Samain, A. and Sun, X. "A New First Year Design Course at the University of Western Ontario", Proc. $2^{\text {nd }}$ CDEN Int. Design Conf., July 18 to 20, Kananaskis, 2005.

[9] Doty, R.T. and William, S.M. "A Practice-Based Senior Design Experience”, Proc. ASEE Annual Conference, June 16 to 19, Montreal, Quebec, 2002.

[10] Surgenor, B.W., Firth, K. and Wild, P.M. "A Course in Mechatronics and Calling the Bluff on Active Learning", Proc. $2^{\text {nd }}$ CDEN Int. Design Conf., July 18 to 20, Kananaskis, Alberta, 2005. 